\title{
Voting Power and the Public Good Index: Some Thoughts
}

\author{
Matthias Weber \\ Swiss Institute of Banking and Finance, University of St. Gallen \& Faculty of \\ Economics and Business Administration, Vilnius University \\ Email: matthias.weber@unisg.ch
}

November 7, 2018

\begin{abstract}
Among the many voting power indices, the public good index (PGI) is one of the less well-known ones. Holler (2018) posits some hypotheses about why this is the case. In response, I share a few thoughts here on voting power in general and about the popularity of the PGI.
\end{abstract}

\section{Introduction}

The Public Good Index (PGI; Holler 1978 and Holler 1982) ${ }^{1}$ is one of multiple indices measuring voting power. Among these measures, the PGI is one of the less wellknown and less used measures. Some people believe that this is unjustified and Holler (2018) posits hypotheses why the PGI may be less appreciated than deserved.

Some of these hypotheses relate to technical properties of the PGI, some others concern who introduced the index and how it was it classified. Manfred Holler asked for comments on his hypotheses. In this short comment, I will first share some rather general thoughts about voting power and the PGI that relate to some of Manfred Holler's hypotheses and afterward comment directly on the hypothesis that the PGI is underappreciated because it was not introduced by a famous game theorist.

\section{Important Properties of Voting Power Indices}

Some of Manfred Holler's other hypotheses about why the PGI has received relatively little attention are concerned with the properties of the index itself and with the value that has been placed on some characteristics of power indices rather than on others (e.g., on local monotonicity). Rather than discussing these properties one by one here (for which I would not be a good candidate), I will discuss another property that power indices can possess, which is in my opinion of crucial importance. I will then later get back to applications of power indices and the PGI. This is the property of a power index to coincide with some form of outcomes. Most power indices do not have this property - at least, when the motivations usually brought forward for these indices are taken at

\footnotetext{
${ }^{1}$ For a very similar idea, see Deegan and Packel (1978). For a discussion of the public good nature, see Holler and Packel (1983).
} 
face value power differences between groups or individuals are different from outcome differences (outcomes could be some sort of utility, in the simplest case linear transferable utility).

Much of the voting power literature is normative in nature. That is, claims are made about which voting systems are fair based on their difference in voting power. However, as these differences in voting power are not differences in outcomes, this seems plainly wrong. Looking at the standard motivation of Penrose's Square Root Rule for two-tier voting systems (Penrose 1946; Banzhaf 1965; for concise but clear descriptions see Turnovec 2009 or Weber 2016), this becomes particularly clear. If you are an individual who favors the adoption of a proposal and the proposal is not adopted, how do you benefit from the representative of your group having been responsible for failure to adopt the proposal? Of course not at all. Probably some scholars noticed that the probability to indirectly influence the outcome in such a setting is different from the probability of getting what one wants already a long time ago, but many certainly didn't. Therefore, voting power differences may have looked like an acceptable normative criterion for judging the fairness of voting systems. However, since Barbera and Jackson (2006), or at the very latest since Laruelle and Valenciano (2005), who call the difference between power and outcomes decisiveness vs. success, one can no longer pretend that minimizing voting power differentials is a useful normative criterion. ${ }^{2}$ In short: After these works, one cannot continue as before! Unfortunately, some scholars seem not to be fully aware of this. Sometimes, one can even see footnotes of the sort "we know that ex-ante power is not identical to ex-post power but follow the literature in sticking with ex-ante power as normative concept". This is utterly wrong in my opinion. All valid normative concepts in the voting (power) literature now must be outcome-based. Except for the Shapley-Shubik index with its motivation in so-called divide-the-dollar games, voting power indices and their motivations are usually not outcome-based. I believe that this is a strong and valid reason for the popularity of the Shapley-Shubik index.

This does not necessarily mean that there is no more room for classical voting power indices. Even indices such as the Banzhaf index or the PGI that do not possess an outcome-based motivation may prove useful, if they are not used as normative fairness criteria but for positive analyses. Of course, in a rational world, which economists have almost exclusively assumed for multiple decades, the normative and positive criteria should coincide. However, there is by now a vast literature documenting boundedly rational and behavior in economic and political situations (accumulated since at least Tversky and Kahneman 1974 and Grether and Plott 1979). Even more, it seems that

\footnotetext{
2 This is hinted at in a very diplomatic way in Kurz et al. (2015): "Social choice articles now appearing in top economics journals are concerned first and foremost with the welfare properties of voting systems; power comes as a distant second or even third ... But welfarist approaches to voting, which focus on measures of success rather than pivotality, can be viewed as part of power index research defined in a sufficiently expansive way."
} 
psychological factors are of crucial important in all economic fields. ${ }^{3}$ As focusing on actual human behavior, in contrast to assuming rational choice, has proved so valuable in all these fields, I do not see why actual human behavior should then not matter in the field of voting power. This means that voting power indices can still be very useful if they have a meaningful positive side to them!

In a way, Weber (forthcoming) can be interpreted as such an attempt to "save" the Banzhaf index. In this work, I investigate preferences over voting systems for assemblies of representatives. More precisely, I investigate whether participants in an incentivized laboratory experiment prefer voting systems that have been designed to approximate equal indirect Banzhaf power over voting systems that approximate equal indirect Shapley-Shubik power in a setting that is as close as possible to the standard motivation of the Banzhaf index (or Penrose's Square Root Rule). My thought was that, while the Banzhaf index is from a theoretical viewpoint worthless as a normative criterion, it may still describe well what kind of voting systems people prefer. If many political scientists, mathematicians, and economists found this concept convincing for multiple decades (as normative criterion), it may be possible that this concept still coincides with people's feeling of fairness. Unfortunately for the Banzhaf index, participants in Weber (forthcoming) preferred voting systems approximating equal indirect Shapley-Shubik power over those approximating equal indirect Banzhaf power. However, this was only a comparison between those two concepts, the PGI and other power indices were not part of the comparison. It could well be that other concepts, that may include ones based on the PGI, are preferred as much as or even more than voting systems approximating equal indirect Shapley-Shubik power.

Of course, analyzing people's preferences over voting systems is not the only possible positive analysis of voting. Other options include analyzing whether power indices have predictive power concerning which coalitions form in democratic institutions with more than two parties (although, it may prove difficult to convincingly disentangle the contributions of political proximity and voting power of different parties to the forming of coalitions). In reality, it is well possible that smaller parties have greater actual power to influence politics than larger parties. Looking for example at Germany, one could easily make the claim that the libertarian party FDP has had more power in the past than other parties despite often rather small vote shares, as the FDP has often been part of the governing coalition (as junior partner of the CDU). When thinking with the intuition of the PGI in mind, this is not necessarily surprising. The small vote share of the FDP was enough to give a coalition of the CDU and the FDP the majority of votes in parliament, so that it would have been unnecessary from the viewpoint of the CDU to coalesce with a larger party than the FDP or with more parties than only with the

\footnotetext{
${ }^{3}$ This includes public finance (Weber and Schram 2017), asset pricing (Kopányi-Peuker and Weber 2018; Weber et al. 2018), and macroeconomics (Hommes et al. 2017; Bertasiute et al. 2018). Also when the behavior of scholars themselves is concerned, where one should maybe expect the most rational behavior, non-rational perceptions are prevalent and important (Weber 2018).
} 
FDP. Indeed, when the PGI was first brought up (Holler 1978), the task was exactly to analyze government formation through voting power indices (for Finland 1948-1978).

However, as mentioned above, it is difficult in such real-world application to disentangle pure theoretical power considerations from political proximity. In the German example, one should not forget that the FDP is also the party that is politically closest to the CDU. It could thus be the case that it is just a coincidence that the FDP had fewer votes than parties ideologically farther from the CDU. The analysis in Holler (1978) focuses on theoretical power alone, without taking political proximity into account. ${ }^{4}$ To obtain a powerful predictor of coalition formation, it seems necessary that power considerations are combined with measures of political proximity. Nowadays, such measures are often available or can easily be calculated. This makes it possible to analyze power indices and political proximity jointly, for example in regression settings. It is not a trivial task to use voting power theory for forecasting coalition formation, but that does not mean that it is not a worthwhile task. I believe that some voting power indices that are not valid normative criteria could prove very useful for such tasks, in particular the PGI.

\section{Reinhard Selten's View on the Missing Popularity of the PGI}

The first hypothesis mentioned by Holler (2018) originates from Reinhard Selten and states that the PGI would be much more used and appreciated, if it had been introduced (and advertised, I would add) by a famous game theorist (from the US, I would add here). This case is very clear, in my view. Unfortunately, in the social sciences (at least in economics and finance, the fields that I am most familiar with, but probably also in other social sciences), there is a very strong focus on scholars from top schools and on scholars from the United States. I would even call this focus a bias. I have little doubt that there is a massive difference in popularity of two equally good concepts if one is introduced by a relatively unknown European author and the other by a famous US American author. I hope that this will change at some point and that ideas from less known scholars will be taken more seriously, but I am a bit pessimistic, at least in the short and medium run. As far as the regional component is concerned, cold comfort for Europeans could be that Asians, South-Americans, and Africans are most likely in an even worse position.

I am therefore convinced that the PGI would be more popular had it been introduced by a leading game theorist in the US. Whether this effect is so strong that the PGI would have become more popular than the Banzhaf index (Banzhaf 1965) or even as popular as the Shapley-Shubik index (Shapley and Shubik 1954) is a different

\footnotetext{
${ }^{4}$ Voting power considerations can be more important than political considerations in some cases. One example may be the recent coalition of Italy's far right with the far left. However, one may also claim that these parties have a lot in common, reaching from their populistic rhetoric over their contempt for institutions of the European Union to their contempt for press freedom and other democratic core values, so that they are not as distant as the simple leftright distinction suggests.
} 
question. I have some doubts about this, but of course, we do not have the counterfactual.

\section{Concluding Remarks}

Should the PGI be used more often? Maybe yes. Rather than discussing the technical properties of this index, I have tried to make another point in this short comment: voting power indices should be used for positive analyses, as almost all of them are not valid normative criteria. They may turn out very useful, though, in describing people's preferences over voting systems (Weber forthcoming) or for forecasting which coalitions will form. The latter was the purpose of the work introducing the PGI (Holler 1978), but successful modern application may want to combine the voting power considerations with considerations of political proximity.

\section{References}

Banzhaf, J. F. III (1965), "Weighted Voting Doesn't Work: A Mathematical Analysis", Rutgers Law Review 19: 317-43.

Barbera, S., \& Jackson, M. O. (2006), "On the weights of nations: Assigning voting weights in a heterogeneous union", Journal of Political Economy, 114(2), 317-339.

Bertasiute, A., Massaro, D., and Weber, M. (2018), "The behavioral economics of currency unions: Economic integration and monetary policy", Bank of Lithuania Working Paper No 49/2018.

Deegan, J., and Packel, E. W. (1978), "A new index of power for simple n-person games", International Journal of Game Theory 7(2): 113-123.

Grether, D. M., \& Plott, C. R. (1979), "Economic theory of choice and the preference reversal phenomenon", The American Economic Review, 69(4), 623-638.

Holler, M.J. (1978), "A Priori Party Power and Government Formation," Munich Social Science Review 1, 25-41.

Holler, M. J. (1982), "Forming coalitions and measuring voting power". Political studies, 30(2), 262-271.

Holler, M. (2018), "The Story of the Poor Public Good Index: An Introduction", Munich Social Science Review.

Holler, M. J., \& Packel, E. W. (1983), "Power, luck and the right index", Zeitschrift für Nationalökonomie, 43(1), 21-29.

Hommes, C. H., Massaro, D., and Weber, M. (2017), "Monetary policy under behavioral expectations: Theory and experiment", Bank of Lithuania Working Paper No 42/2017. 
Tversky, A., \& Kahneman, D. (1974), "Judgment under uncertainty: Heuristics and biases”, Science, 185(4157), 1124-1131.

Kopányi-Peuker, A. and Weber, M. (2018), "Experience does not eliminate bubbles: Experimental evidence", Working Paper, University of St. Gallen.

Kurz, S., Maaser, N., Napel, S., and Weber, M. (2015), "Mostly sunny: a forecast of tomorrow's power index research", Homo Oeconomicus 32 (1), 133-146.

Laruelle, A., \& Valenciano, F. (2005), "Assessing success and decisiveness in voting situations", Social Choice and Welfare, 24(1), 171-197.

Penrose, L. S. (1946), "The elementary statistics of majority voting", Journal of the Royal Statistical Society, 109(1), 53-57.

Shapley, L.S. and M. Shubik (1954), "A Method of Evaluating the Distribution of Power in a Committee System", American Political Science Review 48: 787-792.

Turnovec, F. (2009), "Fairness and squareness: Fair decision making rules in the EU Council?", IES Working Paper (No. 1/2009).

Weber, M., \& Schram, A. (2017), "The Non-equivalence of Labour Market Taxes: A Real-effort Experiment", The Economic Journal 127(604), 2187-2215.

Weber, M., Duffy, J., and Schram, A. (2018), "An experimental study of bond market pricing", The Journal of Finance, 73(4), 1857-1892.

Weber, M. (2016). Two-tier voting: Measuring inequality and specifying the inverse power problem. Mathematical Social Sciences, 79, 40-45.

Weber, M. (2018). The effects of listing authors in alphabetical order: A review of the empirical evidence. Research Evaluation, 27(3), 238-245.

Weber, M. (forthcoming), "Choosing the rules: Preferences over voting systems for assemblies of representatives. Journal of Economic Behavior \& Organization. 